\title{
FURTHER ATTEMPTS AT DATING THE PALYNOLOGICAL SEQUENCE OF THE HULA L07 CORE, UPPER JORDAN VALLEY, ISRAEL
}

\author{
M Weinstein-Evron ${ }^{1} \cdot \mathrm{J} \mathrm{C} \mathrm{Vogel}^{2} \cdot \mathrm{J}_{\text {Kronfeld }^{3}}$ \\ ABSTRACT. The palynological sequence of the Hula L07 core was previously correlated with the global oxygen isotope \\ stages 3-5, based on a radiocarbon age determination and comparison with other Levantine paleoclimatological curves. An \\ attempt was made to validate this correlation with $\mathrm{Th} / \mathrm{U}$ dating. Unlike typical European peat, which is acidic, the soil $\mathrm{pH}$ of \\ the Hula peat is mildly basic. Not only does this contribute to the oxidation of palynomorphs, but it also helps to preserve the \\ carbonate material that can be a variable mixture of allogenic, endogenic, and authigenic components. Each component may \\ represent a different degree of uranium series disequilibrium. The thorium $\left.{ }^{232} \mathrm{Th}\right)$ concentrations of the carbonate are low. \\ Total digestion or acid leach of the sample may not always enable the proper correction for initial thorium. The dating derived \\ from a $\mathrm{NaOH}$-extraction of the organic material, while giving apparently better ages, also suffers from the presence of the car- \\ bonate admixture. It appears that, while ${ }^{14} \mathrm{C}$ dating can be considered suitable for the younger portions of the core, techniques \\ based upon the U-series may not be as efficacious in dating this important record of climatic change.
}

\section{INTRODUCTION}

The Hula Valley preserves a continuous sedimentary record extending back from the present through the Pleistocene and beyond. Valuable environmental proxy data are recorded in the pollen and other fossil record (Horowitz 1973, 1979, 1992, 2001; Ehrlich 1973; Moshkovitz and Magaritz 1987; Weinstein-Evron 1983, 1990; Baruch and Bottema 1999) as well as in the mineralogical (Cowgill 1973), chemical (Hutchinson and Cowgill 1973), and isotopic (Stiller and Hutchinson 1980) constituents of the sediment. Absolute dating of the deposit is, therefore, desirable for calibrating the paleoenvironmental evidence to regional as well as worldwide climate changes. Radiocarbon dating has been carried out upon the younger intervals in the upper part of several cores (Horowitz 1979; Kafri et al. 1983; Stiller and Hutchinson 1980; Baruch and Bottema 1999). The deeper parts of the Hula sedimentary fill containing organics-rich peat or lignite layers largely remain beyond the range of ${ }^{14} \mathrm{C}$. This is the portion that contains a significant record of the Pleistocene. Palynological studies of this core fragment revealed many climatic fluctuations in that period (Horowitz 1979; Weinstein-Evron 1983).

The section between $29.5 \mathrm{~m}$ and $108 \mathrm{~m}$ depth in the Hula L07 core has been used extensively for detailed palynological analysis. The uppermost $29.5 \mathrm{~m}$ of the core were not preserved by the drillers, whose primary aim was the evaluation of the economic potential of the various lignite layers (Kafri and Lang 1979). The deeper portions of the core have not yet been analyzed. The Hula L07 core contains seven "peat" layers at a depth between 29.5-128 m. The lignite layer from $41 \mathrm{~m}$ has been dated to $42,590 \pm 2010$ BP by ${ }^{14} \mathrm{C}$ (Pretoria Radiocarbon Laboratory sample number Pta 2538 ; WeinsteinEvron 1983). This is the only absolute chronological constraint for the palynological study of the core. This datum is at the limit of the ${ }^{14} \mathrm{C}$ technique, which obviates the possibility of obtaining additional finite ${ }^{14} \mathrm{C}$ dates at greater depths. The pollen sequence found in the interval between $29.5 \mathrm{~m}$ down to $75 \mathrm{~m}$ reveals a pattern of climatic change that was interpreted as being correlative to isotope stages 3-4 (Weinstein-Evron 1983). It has been argued (Weinstein-Evron 1990) that the Hula L07 sequence down to $75 \mathrm{~m}$ is comparable to that of the Ghab palynological sequence encompassing

\footnotetext{
${ }^{1}$ Laboratory of Palynology, Zinman Institute of Archaeology, University of Haifa, Haifa 31905, Israel. Email: evron@ research.haifa.ac.il.

${ }^{2}$ Quaternary Dating Research Unit, EMA/CSIR, P. O. Box 395, Pretoria, South Africa. Email: jvogel@ csir.co.za. ${ }^{3}$ Department of Geophysics and Planetary Sciences, Tel Aviv University, Tel Aviv 69978, Israel. Email: yoelk@ccsg.tau.ac.il.
}

(C) 2001 by the Arizona Board of Regents on behalf of the University of Arizona Radiocarbon, Vol 43, Nr 2B, 2001, p 561-570

Proceedings of the 17 th International ${ }^{14} \mathrm{C}$ Conference, edited by I Carmi and E Boaretto 
global oxygen isotope stages 1-4 (Niklewski and van Zeist 1970), some $300 \mathrm{~km}$ to the north, for the same time period. The picture for approximately the next $30 \mathrm{~m}$ of the Hula L07 core is less coherent due to a hiatus in the palynological record (Weinstein-Evron 1983) and the apparent increasing rates of compaction with depth (Weinstein-Evron 1987). The sequence of this portion of the core has been tentatively correlated with isotope stage 5 and the end of isotope stage 6. In the Hula L07 core, the $75 \mathrm{~m}$ interval was placed at about $75 \mathrm{ka} \mathrm{BP}$ - consistent with an apparent uniform rate of sedimentation of $1 \mathrm{~m} / 1000 \mathrm{yr}$ for the core. This is similar to the sedimentation rate derived from the single ${ }^{14} \mathrm{C}$ datum. Other than this extrapolation, an absolute chronological framework has not been determined for this well-studied core so far. An U/Th study was, therefore, carried out as an attempt to date the various peat horizons and verify this rate of sedimentation.

The dating of peat by the ${ }^{230} \mathrm{Th} /{ }^{234} \mathrm{U}$ method would appear to be attractive, because it offers the potential of extending the absolute dating back to $300,000 \mathrm{yr}$. The method is based upon the separation of the more soluble uranium parent from its thorium daughter during weathering. When the uranium is once again immobilized (e.g. being precipitated or adsorbed) it should be free of its ${ }^{230} \mathrm{Th}$ daughter $\left({ }^{230} \mathrm{Th} /{ }^{234} \mathrm{U}=0\right)$. The ${ }^{230} \mathrm{Th} /{ }^{234} \mathrm{U}$ ratio increases over time with the ingrowth of the daughter (its half life is approximately 75,200 yr) until secular equilibrium is attained $\left({ }^{230} \mathrm{Th} /{ }^{234} \mathrm{U}=1\right.$ ). If a closed system is maintained, the amount of ${ }^{230} \mathrm{Th}$ builds up solely as a function of time. As elemental thorium (including both ${ }^{230} \mathrm{Th}$ and ${ }^{232} \mathrm{Th}$, the latter is not associated with the uranium-decay series) can be carried by sediment transported into the basin, some ${ }^{230} \mathrm{Th}$ may be introduced that is not associated with the in situ decay of ${ }^{234} \mathrm{U}$. Additions of a detrital ${ }^{230} \mathrm{Th}$ component are generally assumed when the presence of ${ }^{232} \mathrm{Th}$ is detected. A correction must then be made for the presence of this allogenic ${ }^{230} \mathrm{Th}$ contaminant. However, if old marine carbonate (having high total $\mathrm{U} /{ }^{232} \mathrm{Th}$ ratios, but ${ }^{230} \mathrm{Th} /{ }^{234} \mathrm{U}=1$ ) were to be one of the contaminating components of the sediment mixture, the ${ }^{232} \mathrm{Th}$ concentration would be very small and an insufficient correction for the initial ${ }^{230} \mathrm{Th}$ would result. Dating of peat from Europe (Vogel and Kronfeld 1980; van der Wijk et al. 1986, 1988; Heijnis and van der Plicht 1992) and Canada (der Vernal et al. 1986) has been carried out with relative success. Lignites in sediment cores (representing 16 samples in total) taken at three different sites in the Hula Valley were previously analyzed by the ${ }^{230} \mathrm{Th} /{ }^{234} \mathrm{U}$ method (Kafri et al. 1983). Though puzzling stratigraphic inconsistencies were encountered, one core yielded increasing age (for 6 of 7 samples) with depth, which was consistent with the ${ }^{14} \mathrm{C}$ data from the upper section of the core. It seemed, therefore, worthwhile to apply the ${ }^{230} \mathrm{Th} /{ }^{234} \mathrm{U}$ dating method to the Hula LO7 core in order to extend its absolute chronology.

\section{The Hula Basin}

The small Hula basin occupies approximately $150 \mathrm{~km}^{2}$ of Israel's northernmost extension of the Arava-Jordan Rift system (Figure 1). It lies nestled between the Hills of Galilee and the Golan Plateau. To the west, the rims of the valley are constructed mainly of Cretaceous (Cenomanian-Turonian age dolomites and limestones) and Early Tertiary (predominantly chalks and limestones) sedimentary rocks. To the east, south, and north, Neogene basalts cover the basin rims.

The Jordan River drains into the Hula Basin from the north and continues south out of the basin. The Hula Group sediments were deposited in a freshwater environment that alternated between shallow lake conditions that laid down either chalks, marls, or organics-rich clays and marshes that deposited peat-sometimes with basaltic intercalations (Horowitz 1973). The lignite that developed is poor in quality (Kafri and Lang 1979), having high ash residues (Table 1). The residue is a variable mixture of carbonate and of non-carbonate minerals, primarily clay and other fine alumino-silicates. 


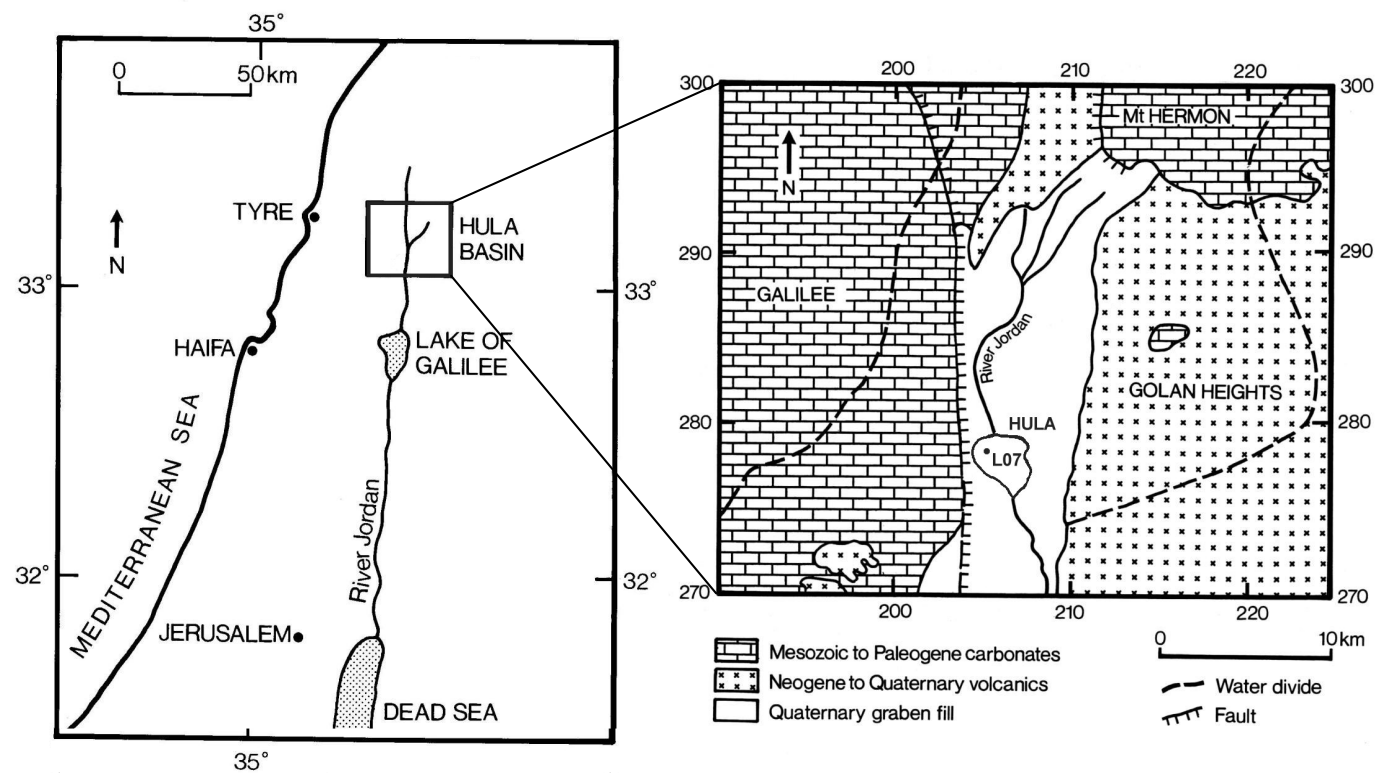

Figure 1 Location map of the Hula Basin and Core L07.

Table 1 Uranium-series isotopic data for Hula Peat (Core L07).

\begin{tabular}{|c|c|c|c|c|c|c|}
\hline $\begin{array}{l}\text { Sample } \\
\text { (depth) }\end{array}$ & $\begin{array}{l}\text { Ash } \\
(\%)\end{array}$ & $\begin{array}{l}{ }^{234} \mathrm{U} /{ }^{238} \mathrm{U} \\
\text { activity ratio }\end{array}$ & $\begin{array}{c}\mathrm{U} \\
(\mathrm{ppm})\end{array}$ & $\begin{array}{c}\text { Th } \\
(\mathrm{ppm})\end{array}$ & $\begin{array}{l}{ }^{230} \mathrm{Th} /{ }^{232} \mathrm{Th} \\
\text { activity ratio }\end{array}$ & $\begin{array}{l}{ }^{230} \mathrm{Th} /{ }^{234} \mathrm{U} \\
\text { ratio activity }\end{array}$ \\
\hline \multicolumn{2}{|c|}{ Jordan River Water } & $1.89 \pm 0.10$ & $\begin{array}{l}0.00033 \\
\pm 0.00002\end{array}$ & & & \\
\hline \multicolumn{2}{|c|}{$\begin{array}{l}\text { Jordan River Surface } \\
\text { Sediment } \\
\text { (entering Hula) }\end{array}$} & $1.39 \pm 0.09$ & $0.57 \pm 0.04$ & $1.26 \pm 0.10$ & $1.85 \pm 0.16$ & $1.02 \pm 0.09$ \\
\hline \multicolumn{7}{|c|}{ Peats: acid leached } \\
\hline $29.75 \mathrm{~m}$ & 89 & $1.56 \pm 0.03$ & $13.0 \pm 0.5$ & $1.2 \pm 0.2$ & $27.2 \pm 4.3$ & $0.52 \pm 0.04$ \\
\hline $34.5 \mathrm{~m}$ & 74 & $1.55 \pm 0.02$ & $11.1 \pm 0.3$ & $1.3 \pm 0.2$ & $24.9 \pm 3.2$ & $0.60 \pm 0.03$ \\
\hline $40.9 \mathrm{~m}$ & 48 & $1.48 \pm 0.02$ & $9.3 \pm 0.2$ & $1.7 \pm 0.2$ & $19.9 \pm 1.2$ & $0.77 \pm 0.04$ \\
\hline $49.8 \mathrm{~m}$ & nd & $1.53 \pm 0.05$ & $11.0 \pm 0.7$ & $0.8 \pm 0.2$ & $28.3 \pm 6.2$ & $0.49 \pm 0.05$ \\
\hline $54 \mathrm{~m}$ & 52 & $1.43 \pm 0.05$ & $11.4 \pm 0.8$ & $3.2 \pm 0.2$ & $14.3 \pm 0.9$ & $0.92 \pm 0.08$ \\
\hline $93.5 \mathrm{~m}$ & 34 & $1.52 \pm 0.07$ & $3.5 \pm 0.1$ & $2.6 \pm 0.2$ & $6.4 \pm 0.34$ & $1.04 \pm 0.07$ \\
\hline $128 \mathrm{~m}$ & 55 & $1.16 \pm 0.05$ & $3.3 \pm 0.2$ & $1.7 \pm 0.2$ & $6.0 \pm 0.5$ & $0.82 \pm 0.06$ \\
\hline \multicolumn{7}{|c|}{ Peats: $\mathrm{NaOH}$ extraction } \\
\hline $29.75 \mathrm{~m}$ & 89 & $1.48 \pm 0.09$ & $3.3 \pm 0.16$ & $0.41 \pm 0.014$ & $48.4 \pm 17.3$ & $0.14 \pm 0.01$ \\
\hline $34.5 \mathrm{~m}$ & 74 & $1.59 \pm 0.13$ & $0.23 \pm 0.02$ & $0.13 \pm 0.04$ & $28.4 \pm 8.3$ & $0.34 \pm 0.02$ \\
\hline $36.9 \mathrm{~m}$ & 70 & $1.73 \pm 0.11$ & $0.16 \pm 0.01$ & $0.13 \pm 0.03$ & $17.2 \pm 3.5$ & $0.28 \pm 0.02$ \\
\hline $40.9 \mathrm{~m}$ & 48 & $1.50 \pm 0.03$ & $7.19 \pm 0.24$ & $0.78 \pm 0.06$ & $23.0 \pm 1.8$ & $0.52 \pm 0.02$ \\
\hline $93.5 \mathrm{~m}$ & 34 & $1.30 \pm 0.05$ & $0.48 \pm 0.15$ & $0.51 \pm 0.04$ & $3.72 \pm 0.35$ & $0.41 \pm 0.02$ \\
\hline $110 \mathrm{~m}$ & nd & $1.28 \pm 0.04$ & $3.69 \pm 0.16$ & $0.54 \pm 0.04$ & $19.2 \pm 1.4$ & $0.65 \pm 0.03$ \\
\hline $128 \mathrm{~m}$ & 55 & $1.28 \pm 0.04$ & $0.60 \pm 0.04$ & $0.39 \pm 0.04$ & $4.0 \pm 0.4$ & $0.63 \pm 0.05$ \\
\hline \multicolumn{7}{|c|}{ Mollusc shells (analysis by Dr R Hausmann, Köln): } \\
\hline $112 \mathrm{~m}$ & & $1.95 \pm 0.34$ & 0.73 & 0.5 & $2.53 \pm 0.58$ & $1.71 \pm 0.28$ \\
\hline $115 \mathrm{~m}$ & & $1.29 \pm 0.44$ & 0.2 & 3.7 & $1.54 \pm 0.30$ & $6.30 \pm 1.59$ \\
\hline
\end{tabular}




\section{SAMPLING AND METHODS}

Core LO7 is a long $(160 \mathrm{~m})$ sediment core drilled in the north central $\left(33^{\circ} 10^{\prime} \mathrm{N}, 35^{\circ} 40^{\prime} \mathrm{E}\right)$ part of the Hula Basin (Figure 1). Samples for dating were taken from the organics-rich ("peat") layers found at depths between $29.75-128 \mathrm{~m}$. As already mentioned, the $29.5 \mathrm{~m}$ level serves as the effective top of the core; the uppermost section was not preserved during the coring.

Samples were taken for alpha spectrometric analysis with aliquots generally being subjected to two different chemical procedures. One aliquot was subjected to an acid leach while another was subjected to an alkaline leach. The latter method was attempted because of the rather special nature of the "peat". Unlike most true European peat that is acidic, the Hula peat is mildly basic (Ravikovitch 1969, 1971). The palynomorphs in the "peat" are oxidized and preserved only in the intervening clayey layers. The basic conditions also lead to the preservation of carbonate material within the lignite layers in the Hula sediments, something that does not occur in the European peat. This carbonate can be material eroded from the surrounding hills (in which case secular equilibrium in the uranium series should prevail). Endogenic carbonate, as well as biogenic carbonate, may also be present. In the latter two cases it would be expected that the ${ }^{230} \mathrm{Th} / 234 \mathrm{U}$ should be far from the secular equilibrium. Mollusc shells, primarily gastropods, are generally plentiful throughout the section (Moshkovitz and Magaritz 1987). While a total dissolution of the sediment, or an acid leach would dissolve all of the various carbonate phases, an alkaline extraction was used in an attempt to separate the organic phase from the silicate and carbonate detritus.

For the acid leach, $10 \mathrm{~g}$ of air-dried material that had been ground to a powder in an agate mortar were combusted over a Bunsen burner. Powdered material was then leached overnight at $60^{\circ} \mathrm{C}$ using $3 \mathrm{~N}$ HCI. The solution was filtered and a ${ }^{232} \mathrm{U} /{ }^{28} \mathrm{Th}$ spike added. Following ion exchange and solvent extraction procedures the purified uranium and thorium metals were electroplated on stainless steel planchets and were isotopically analyzed by alpha spectrometry.

For the organic extraction $10 \mathrm{~g}$ of air-dried powdered material was placed in a $600 \mathrm{~mL}$ beaker containing $0.1 \mathrm{~N} \mathrm{NaOH}$ solution. This mixture was placed in an oven at $60^{\circ} \mathrm{C}$ for $48 \mathrm{hr}$, with occasional stirring. The solution was then brought to boiling for $10 \mathrm{~min}$. After settling and air-cooling the liquid phase was filtered. The liquid was then evaporated and ashed in a quartz crucible. $3 \mathrm{~N} \mathrm{HCl}$ was then used to leach the residue in the crucible. The leachate was similarly spiked and the radiometals extracted, purified, and analyzed isotopically by alpha-spectrometry. In addition, a sample of Jordan River water and a sample of the surface sediments that are entering the Hula Basin were collected and radiometrically analyzed. The river sediment was air-dried and ground in an agate mortar and subjected to a $3 \mathrm{~N} \mathrm{HCl}$ acid leach, and the same chemical procedures as above. Likewise, in the laboratory the uranium isotopes were extracted from the river water by coprecipitation along with ferric hydroxide at a $\mathrm{pH}$ of 8 from a $20 \mathrm{~L}$ sample that had been acidified in the field to a $\mathrm{pH}=1$ and had a ${ }^{232} \mathrm{U}$-spike and ferric nitrate carrier added.

\section{RESULTS}

The isotopic data are presented in Table 1. Also included in Table 1 are two analyses for gastropod shells taken from the $112 \mathrm{~m}$ and $115 \mathrm{~m}$ intervals that were analyzed by Dr R Hausmann of the University of Köln (O Katzenberger, personal communication 1987). They provide an indication of the degree to which the biogenic carbonate fraction acts as a closed geochemical system. The percentages of ash remaining after combustion are also reported in Table 1 . The non-organic material constituted $34 \%$ to $89 \%$ by weight of the sample. True peat has less than $25 \%$ ash. This material is a variable mixture of carbonates and clastic silicates. The uranium that is leached from the peaty lay- 
ers varies from 4 to $13 \mathrm{ppm}$. These concentrations are considerably higher than that expected from the marine carbonates and the basalts that surround the basin, or the Jordan River sediment (Rogers and Adams 1969). The most likely process causing uranium enrichment in peaty layers is sorption of dissolved uranium from the water draining into the basin. Soluble uranium can precipitate upon entering a reducing environment. Peat can also sorb dissolved $U$ under oxidizing conditions. The organic material itself contains humic and fulvic acids known for their effectiveness in binding radiometals in solution (Szalay 1958; Zielinski and Meier 1988).

The ${ }^{234} \mathrm{U} /{ }^{238} \mathrm{U}$ activity ratios measured (to evaluate the constancy of an assumed initial ${ }^{234} \mathrm{U} /{ }^{238} \mathrm{U}$ ratio) range between 1.73 and 1.28 ( $\mathrm{NaOH}$ extraction) and between 1.56 and 1.16 (acid leach). The activity ratios are lower than that of the present Jordan River inflow. The ${ }^{234} \mathrm{U} /{ }^{238} \mathrm{U}$ activity ratio of the present surface sediment is 1.4 (Table 1). The old (Cretaceous) carbonate rocks of the surrounding hills should be in secular equilibrium with ${ }^{234} \mathrm{U} /{ }^{238} \mathrm{U}$ activity ratios of 1.0 . It is possible that the lower ratios observed are produced by some degree of mixing of the organic component (which was derived by enrichment from the waters) with an old carbonate component. It is also conceivable that the activity ratio of the drainage water was previously lower, as a result of a change in climate and intensity of weathering. A more rigorous chemical weathering may create less isotopic fractionation at the source. Authigenic and endogenic carbonates formed contemporaneously within the basin should have isotopic ratios similar to the waters from which they were derived.

The thorium concentration varies in the acid soluble leach from 0.8 to $3.2 \mathrm{ppm}$. Thorium, unlike uranium, is not appreciably soluble. It is entirely brought into the peat with the detrital component. This is noted by the close similarity between the thorium content of the acid leached fraction and that of the present day river sediment. Two samples $(54 \mathrm{~m}$ and $93 \mathrm{~m}$ ) yield higher thorium concentrations. This may reflect a variation in the detrital sediment composition at the time of deposition. The ${ }^{230} \mathrm{Th} /$ ${ }^{232} \mathrm{Th}$ activity ratios range from approximately 6 to 28 in the acid-leach fraction and between 4 and 48 for the $\mathrm{NaOH}$ extract. At first glance, such high ratios would generally indicate that the correction for detrital ${ }^{230} \mathrm{Th}$ contamination in the calculation of the absolute age should be feasible and, moreover, in most cases it should even be minor. The Jordan River sediment has a ${ }^{230} \mathrm{Th} /{ }^{234} \mathrm{U}$ ratio that is in secular equilibrium. With one exception, the ${ }^{230} \mathrm{Th} /{ }^{234} \mathrm{U}$ activity ratios of both the acid and $\mathrm{NaOH}$ peat extracts are all below equilibrium values. One sample, the acid leach from $93.5 \mathrm{~m}$, exhibited a slight excess of ${ }^{230} \mathrm{Th}$ compared to its parent, though the ${ }^{234} \mathrm{U} /{ }^{238} \mathrm{U}$ activity ratio is similar to the ratio in the samples above it. This is also similar to the ${ }^{234} \mathrm{U} /{ }^{238} \mathrm{U}$ activity ratio of the sediment that enters the Hula Basin. Perhaps, in this context, the mollusc shell analysis may be relevant. Both analyses indicate that the shells do not behave as a closed system. Significant excess ${ }^{230} \mathrm{Th}$ is present relative to ${ }^{234} \mathrm{U}$.

The relatively high ${ }^{230} \mathrm{Th} /{ }^{232} \mathrm{Th}$ ratios raised initial expectations that core LO7 could be dated by the ${ }^{230} \mathrm{Th} /{ }^{234} \mathrm{U}$ method with a correction being made for the presence of initial thorium. The calculated apparent ${ }^{230} \mathrm{Th} /{ }^{234} \mathrm{U}$ ages are presented in Table 2. The correction (Schwarcz 1980) for an initial ${ }^{230} \mathrm{Th} /{ }^{232} \mathrm{Th}$ ratio $(\mathrm{F})$ of 0,1 , and 1.5 are used, which covers the range of most mineral detritus. Kafri and co-workers (1983) in their dating of the Hula peat used an initial ${ }^{230} \mathrm{Th} /{ }^{232} \mathrm{Th}$ ratio of 0.8 for their calculations of the detrital thorium component. A plot of the ${ }^{230} \mathrm{Th} /{ }^{234} \mathrm{U}$ ages as a function of depth using a correction value for an initial ${ }^{230} \mathrm{Th} /{ }^{232} \mathrm{Th}$ ratio $(\mathrm{F}=1)$ is presented in Figure 2.

The acid leach fraction that dissolves the carbonate of all types, does not yield a consistent age versus depth relationship. The calculated ages are sensitive to the correction factors used, yet no consistent pattern is obtained for any one specific correction factor. The ages for the upper interval of the core are too old compared to the ${ }^{14} \mathrm{C}$ value. 
Table $2{ }^{230} \mathrm{Th} /{ }^{234} \mathrm{U}$ ages (Core L07). Apparent age $\left(\times 10^{3} \mathrm{yr}\right)$ using correction for initial ${ }^{230} \mathrm{Th} /{ }^{232} \mathrm{Th}$

\begin{tabular}{lccc}
\hline & 0 & 1 & 1.5 \\
\hline Peat: acid extract & & & \\
$29.75 \mathrm{~m}$ & $77 \pm 9$ & 70 & 66 \\
$34.5 \mathrm{~m}$ & $93 \pm 8$ & 78 & 77 \\
$40.9 \mathrm{~m}$ & $137 \pm 17$ & 107 & 97 \\
$50 \mathrm{~m}$ & $71 \pm 10$ & 65 & 63 \\
$54 \mathrm{~m}$ & $210 \pm 52$ & 204 & 201 \\
$93.5 \mathrm{~m}$ & $>250$ & $>250$ & $>250$ \\
$128 \mathrm{~m}$ & $173 \pm 31$ & 158 & 130 \\
Peat: NaOH extract & & & \\
$29.75 \mathrm{~m}$ & $16 \pm 1$ & 15 & 15 \\
$34.5 \mathrm{~m}$ & $42 \pm 4$ & 39 & 38 \\
$36.9 \mathrm{~m}$ & $34 \pm 3$ & 31 & 30 \\
$40.9 \mathrm{~m}$ & $76 \pm 5$ & 73 & 71 \\
$93 \mathrm{~m}$ & $55 \pm 4$ & 43 & 36 \\
$110 \mathrm{~m}$ & $108 \pm 9$ & 105 & 103 \\
$128 \mathrm{~m}$ & $102 \pm 13$ & 84 & 75 \\
Mollusc shells & & & \\
$112 \mathrm{~m}$ & N.C. & N.C. & N.C. \\
$115 \mathrm{~m}$ & N.C. & N.C. & N.C. \\
\hline N.C.= not calculable & & &
\end{tabular}

The $\mathrm{NaOH}$ extraction yields ages that are less sensitive to the correction factor used. The calculated ages are generally younger, yielding a better depth to age relationship (Figure 2). The 41-m-deep sample gives an apparent age (approximately $70 \mathrm{ka}$ ) that is too old by almost a factor of two compared to ${ }^{14} \mathrm{C}$, of approximately $42 \mathrm{ka}$. The acid leach fraction for the $41 \mathrm{~m}$ sample gives an even older apparent age of $100 \mathrm{ka}$.

\section{DISCUSSION}

In the Hula basin water with an alkaline $\mathrm{pH}$ does not dissolve the influx of allogenic carbonate, nor does it inhibit the growth and preservation of mollusc shells and other carbonates. All of these different carbonate components may be in different states of secular equilibrium with respect to $U$ and Th: 1) the marine carbonate detritus should be in secular equilibrium, 2) the biogenic carbonates as represented by the molluscs can be open systems (Kaufman et al. 1971), which are seen in the Hula to exhibit excess ${ }^{230} \mathrm{Th}$ (Tables 1 and 2), 3) the endogenic carbonate, or the calcium carbonate that precipitated inorganically within the basin, may be material that can yield valid U-series ages (Kaufman 1971). Any total dissolution or acid leach method would dissolve this complex assemblage without revealing instances in which a significant detrital thorium component (mostly ${ }^{230} \mathrm{Th}$ in this case) may be present.

In Europe the acidic environment in which peats form would not allow for the preservation of a carbonate mineral phase. Detrital carbonates that are transported into the basin would dissolve, as would the biogenic and endogenic carbonates. The only appreciable thorium contamination would 


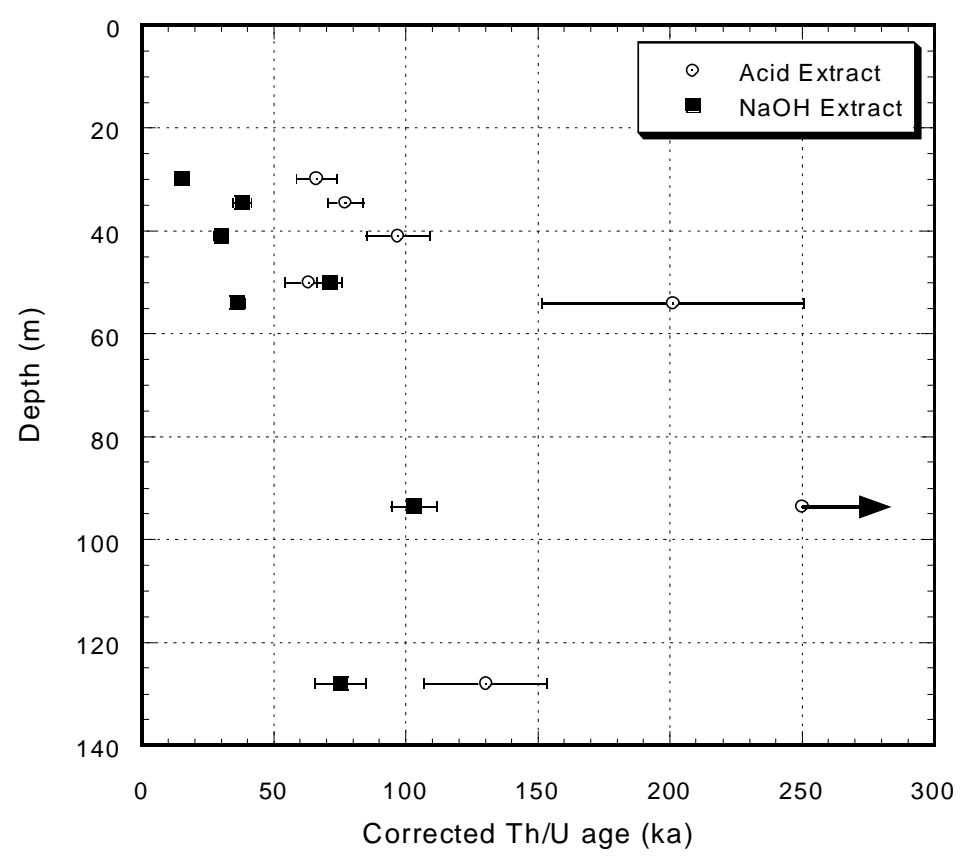

Figure 2 A plot of the corrected ages versus depth relationship for both the acid and $\mathrm{NaOH}$ leaches. The $\mathrm{Th} / \mathrm{U}$ ages are corrected for detrital thorium contamination having an initial ${ }^{230} \mathrm{Th} /{ }^{232} \mathrm{Th}$ ratio of 1 .

be associated with the insoluble alumino-silicates. The ${ }^{230} \mathrm{Th}$ contamination could be corrected for, assuming constancy of an initial ${ }^{230} \mathrm{Th} / 232 \mathrm{Th}$ ratio.

The apparent age relationship obtained from the acid leach in Core LO7 is similar in trend and magnitude to that encountered in the study by Kafri et al. (1983), who used a total dissolution technique. The non-constancy in the increase in age as a function of depth can be attributed to the inclusion and variability of the mixture of a carbonate component, as discussed above, with river borne detritus (with a present day ${ }^{230} \mathrm{Th} / 232 \mathrm{Th}$ activity ratio of 1.85 ). There is no a priori reason why the initial ${ }^{230} \mathrm{Th} / 232 \mathrm{Th}$ ratio of a detrital sediment cannot be different at various intervals of a basin sedimentary sequence. Such a situation would complicate any correction procedure. Indeed, a sediment that is composed of a mixture of carbonates (both young and old) with a low $\mathrm{Th} / \mathrm{U}$ ratio, and weathered igneous material with a much higher $\mathrm{Th} / \mathrm{U}$ ratio, would need a correction factor that takes into consideration the variable sediment composition within the sediment profile in the Hula (Hutchinson and Cowgill 1973).

The "apparent ages" derived from the acid leach or total digestion may be too old due to the underestimation of initial ${ }^{230} \mathrm{Th}$. The dissolving of the carbonate mollusc shells may also adversely affect the ages, because it is not a reliable material to date (Kaufman et al. 1971). The $\mathrm{NaOH}$ extraction yields sedimentation rates that are more in line with the rate of $1 \mathrm{~m} / 1000 \mathrm{yr}$ as determined by the one ${ }^{14} \mathrm{C}$ age from the $\mathrm{LO} 7$ core and for the upper intervals of other cores in the basin that have been dated by ${ }^{14} \mathrm{C}$ (e.g. Horowitz 1979; Kafri et al. 1983; Bottema and Baruch 1999). Yet, here too the "apparent ages" calculated from the $\mathrm{NaOH}$ extraction data are subject to a high degree of uncertainty and error. The extraction did not remove only the authigenic ${ }^{230} \mathrm{Th}$ as indicated by the presence of ${ }^{232} \mathrm{Th}$ 
in the samples. Apparently, the organic acids were able to leach, to a certain extent, the surfaces of the intercalated clays. It is not likely that under the highly basic conditions of the $\mathrm{NaOH}$ extraction that either $\mathrm{U}$ or Th were mobilized. There also exists the possibility that the organic materials themselves were not entirely isotopically closed systems. The oxidizing alkaline conditions promote open-system behavior of the organic matter. The high amount of uranium contained upon the surfaces of thin organic films also offers the possibility of loss of the daughter nuclides, either ${ }^{234} \mathrm{U}$ or ${ }^{230} \mathrm{Th}$, by alpha-recoil. It is possible that some of these recoiled nuclei were not ejected back into the organic phase, but may have passed into solution or to the detrital clastic material that is intimately admixed and covered by the U-rich organic films.

The paleoclimatic reconstructions based on palynological analyses from core L07 and those based on isotopes in speleothems from Israeli caves (Bar-Matthews et al. 1999; Frumkin et al. 1999; Frumkin 2000; Vaks et al. 2001) are similar. The chronological framework of the latter has been achieved through detailed and precise $\mathrm{Th} / \mathrm{U}$ dating. This suggests that the chronological framework defined by the ${ }^{14} \mathrm{C}$ datum for the $\mathrm{LO} 7 \mathrm{Hula}$ core is valid. By contrast, the $\mathrm{Th} / \mathrm{U}$ dates for the deeper sections of the core are problematic. The $\mathrm{NaOH}$ extraction appears to yield "apparent age" estimates that are more in line with the ${ }^{14} \mathrm{C}$ date. However, neither of the two extraction methods utilized in this study appears to consistently yield plausible absolute ages. Likewise, a total dissolution technique (Kafri et al. 1983) may not always yield reliable corrected absolute ages. The primary reason seems to be the ubiquitous and variable mixture of carbonate components within the peaty layers. The high $\mathrm{pH}$ of this peat has not only hindered the palynological study by oxidizing the palynomorphs, but it has also adversely affected the geochronology by retarding the dissolution of the carbonates. Unfortunately, it is considered that these conditions may not only adversely affect the dating of the peat by the ${ }^{230} \mathrm{Th} /{ }^{234} \mathrm{U}$ method, but all methods of dating of the peaty layers that depend upon a closed U-series system for the environmental dose rate, such as ESR and TL.

The Hula peats barely justify the term "peat" in the true sense. However, their designation as such has attracted efforts to date them. The potential paleoclimatological and archaeological importance of dating the Hula sediments will undoubtedly draw attempts in the future. ${ }^{14} \mathrm{C}$ dating is reliable for the young sediment layers, but these are only a small portion of the stratigraphic section. $\mathrm{Th} / \mathrm{U}$ dating of the deeper sections may yield reliable ages. However, this method is fraught with potential inaccuracies as a result of the preservation of carbonate material. An accurate age determination needs to take into consideration a correction for the extraneous Th isotopes, but their presence and their relative importance may be difficult to evaluate. The question is not simply whether such components exist, but whether they are present in sufficient quantity as to render the resulting ages valueless. In the younger section of the Hula, the validity of $\mathrm{Th} / \mathrm{U}$ ages can be evaluated by comparing with ${ }^{14} \mathrm{C}$ dates for the same interval. However, the different carbonate components vary both with depth in any individual core as well as laterally across the Hula basin. Therefore, a concordance with ${ }^{14} \mathrm{C}$ ages in the upper sections cannot be assumed to necessarily hold true when extrapolated to depth. Moreover, dating of deeper horizons in the core, by assuming a constant ${ }^{14} \mathrm{C}$-based rate of sedimentation extrapolated from the upper portions may not be generally tenable in the Hula, since the sedimentation rate in the basin was not uniform over time. Unlike the application of the $\mathrm{Th} / \mathrm{U}$ technique to speleothems, corals, or true peat, for example, where a single $\mathrm{Th} / \mathrm{U}$ date can be accepted as defining a valid date, the validity of Th/U dates of the Hula lignites should only be accepted after evaluating a series of such analyses taken in sequence from different horizons in a core. This is perhaps illustrated in the previous Th/U study (Kafri et al. 1983) whereby the ages of most samples in one core appear to yield reliable dates, while at another site there is no consistency between the $\mathrm{Th} / \mathrm{U}$ ages and depth. 
This work suggests that future dating attempts avoid the "peat" and perhaps concentrate mainly on using new methods to date the detrital layers. One such method that should be investigated is optically stimulated luminescence (Huntley et al. 1985). In this technique mineral grains (preferably common quartz) act as dosimeters recording the amount of radiation that they have been exposed to since they were deposited, similar in principle to thermoluminescence (TL). However, unlike TL, which relies upon heating for zeroing the clock, the zeroing in OSL is achieved by the exposure to sunlight during transportation to the site of deposition. Thus, this method offers the potential to date the Hula basin sediments beyond the limit of ${ }^{14} \mathrm{C}$.

\section{REFERENCES}

Bar-Matthews M, Ayalon A, Kaufman A, Wasserburg GJ. 1999. The Eastern Mediterranean paleoclimate as a reflection of regional events: Soreq cave, Israel. Earth and Planetary Science Letters 166:85-95.

Baruch U, Bottema S. 1999. A new pollen diagram from Lake Hula: vegetational, climatic, and anthropogenic implications. In: Kawanabe H, Coulter GW, Roosevelt AC, editors. Ancient lakes: their cultural and biological diversity. Belgium: Kenobi Productions. p 75-86.

Cowgill UM. 1973. The waters of Merom: a study of Lake Huleh II. The mineralogy of a $54 \mathrm{~m}$ core. Archive fur Hydrobiologie 71:421-74.

der Vernal A, Causse C, Hillaire-Marcel C, Mott RJ, Occhietti S. 1986. Palynostratigraphy and U/Th ages of Upper Pleistocene interglacial and interstadial deposits on Cape Breton Island, eastern Canada. Geology 14:554-57.

Ehrlich A. 1973. Quaternary diatoms of the Hula Basin (northern Israel). Geological Survey of Israel, Bulletin 58:1-38.

Frumkin A, Ford DC, Schwarcz HP. 1999. Continental oxygen isotopic record of the last 170,000 years in Jerusalem. Quaternary Research 51:317-27.

Frumkin A. 2000. Paleoclimate and vegetation of the last glacial cycles in Jerusalem from a speleothem record. Global Biogeochemical Cycles 14:863-70.

Heijnis H, van der Plicht J. 1992. Uranium/thorium dating of Late Pleistocene peat deposits in NW Europe, uranium/thorium isotope systematics and open system behavior of peat layers. Chemical Geology 94:16171.

Horowitz A. 1973. Development of the Hula Basin, Israel. Israel Journal of Earth Sciences 22:107-39.

Horowitz A. 1979. The Quaternary of Israel. New York: Academic Press.

Horowitz A. 1992. Palynology of Arid Lands. Amsterdam: Elsevier.

Horowitz A. 2001. The Jordan Rift Valley. Lisse: A.A. Balkema. 730 p.

Hutchinson GE, Cowgill UM. 1973. The waters of Merom: a study of Lake Huleh III. The major chemical constituents of a $54 \mathrm{~m}$ core. Archive fur Hydrobiologie 72:145-85.

Huntley DJ, Godfrey-Smith DI, Thewalt MLW. 1985. Optical dating of sediments. Nature 313:105-7.
Kafri U, Kaufman A, Magaritz M. 1983. The rate of Pleistocene subsidence and sedimentation in the Hula Basin as compared with those of other time spans in other Israeli tectonic regions. Earth and Planetary Science Letters 65:126-32.

Kafri U, Lang B. 1979. Hula Lignite Project: geological report. Israel Geological Survey, Report Hydro/3/79. $85 \mathrm{p}$.

Kaufman A. 1971. U-series dating of Dead Sea carbonates. Geochimica et Cosmochimica Acta 35:1269-81.

Kaufman A, Broecker WS, Ku TL, Thurber DL. 1971. The status of U-series methods of dating molluscs. Geochimica et Cosmochimica Acta 35:1155-83.

Moshkovitz S, Magaritz M. 1987. Stratigraphy and isotope records of Middle and Late Pleistocene molluscs from a continuous corehole in the Hula Basin, northern Jordan Valley, Israel. Quaternary Research 28: 226-37.

Niklewski J, van Zeist W. 1970. A Late Quaternary pollen diagram from northwestern Syria. Acta Botanica Neerlandica 19: 737-54.

Ravikovich S. 1969. Manual and map of soils of Israel. The Hebrew University, Jerusalem: The Magnes Press.

Ravikovich S. 1971. Soils of Israel. Tel Aviv: Kibbutz Meuchad Publishing.

Rogers JJW, Adams JAS. 1969. Uranium. In: Wedepohl $\mathrm{KH}$, editor. Handbook of Geochemistry. Berlin: Springer-Verlag.

Schwarcz HP. 1980. Absolute age determination of archaeological sites by uranium series dating of travertines. Archaeometry 22:3-24.

Stiller M, Hutchinson GE. 1980. The waters of Merom: a study of Lake Huleh VI. Stable isotopic composition of carbonates of a $54 \mathrm{~m}$ core, paleoclimatic and paleotrophic implications. Archive fur Hydrobiologie 89: 275-302.

Szalay A. 1958. The significance of humus in the geochemical enrichment of uranium. In: Peaceful uses of Atomic Energy, Survey of Raw Materials Resources, 2. Geneva: United Nations. p 187-91.

van der Wijk A, El-Daoushy F, Arends AR, Mook WG. 1986. Dating peat with U/Th disequilibrium: some geochemical considerations. Chemical Geology 59: 283-92. 
van der Wijk A, Mook WG, Ivanovich M. 1988. Correction for environmental ${ }^{230} \mathrm{Th}$ in U/Th dating of peat. Science of the Total Environment 70:19-40.

Vaks A, Bar-Matthews M, Ayalon A, Frumkin A, Kaufman A, Matthews A, Segal J. 2001. Pleistocene paleoclimate evidence from the speleothem record of a karstic cave located at the desert boundary-MaaleEfraim, Eastern Shomron, Israel. In: Gvirtzman Z, Amit R, editors. Israel Geological Society 2001, Elat, Abstracts. p 124

Vogel JC, Kronfeld J. 1980. A new method for dating peat. South African Journal of Science 76:557-58.

Weinstein-Evron M. 1983. The paleoecology of the Early
Wurm in the Hula Basin, Israel. Paleorient 9:5-19. Weinstein-Evron M. 1987. Subsampling of palynological sequences: techniques and implications. Palynology 11:67-72.

Weinstein-Evron M. 1990. Palynological history of the last pleniglacial in the Levant. In: Kozlowski JK, editor. Les industries à point folicaèes en Europe. Liege: ERAUL 42. p 9-25.

Zielinski RA, Meier AL. 1988. The association of uranium with organic matter in Holocene peat: an experimental leaching study. Applied Geochemistry 3:63143. 